\title{
Audit of CT Reporting Standards in Cases of Intracerebral Haemorrhage at a Comprehensive Stroke Centre in Australia
}

Running title

Audit of CTReporting Standards in ICH

Authors and Affliliations:

Christen D. Barras, MBBS, BMedSci, MMed, PhD, DipSurgAnat, DipOMS, FRANZCR $(1,4)$

Hamed Asadi, MD, PhD, FRANZCR (2)

Pramit M. Phal MBBS, FRANZCR $(3,4)$

Brian M Tress, MD, FRCR, FRANZCR (4)

Stephen M. Davis MD, FRACP, FRCP (Edin) (5)

Patricia M Desmond MSC, MD, FRANZCR (4)

(1) National Hospital for Neurology and Neurosurgery, Queen Square, London, UK

(2) Beaumont Hospital, Dublin, Ireland

(3) Epworth HealthCare Richmond, Victoria, Australia

This is the author manuscript accepted for publication and has undergone full peer review but has not been through the copyediting, typesetting, pagination and proofreading process, which may lead to differences between this version and the Version of Record. Please cite this article as doi: 10.1111/1754-9485.12491

This article is protected by copyright. All rights reserved 
(4) Royal Melbourne Hospital, Department of Radiology, The University of Melbourne, Victoria, Australia

(5) Royal Melbourne Hospital, Department of Neurosciences, The University of Melbourne, Victoria, Australia

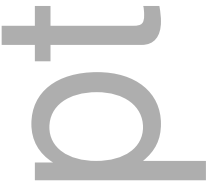

$\square$

Institution at which study was conducted:

Royal Melbourne Hospital,

Department of Radiology,

Grattan St, Parkville

VIC 3050

Australia

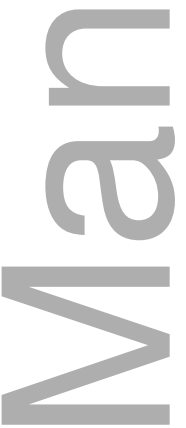

Corresponding Author:

Dr. Christen Barras

c/o Royal Melbourne Hospital

Department of Radiology

Parkville, Victoria, 3050

Australia

E: christenbarras@gmail.com

M: + 447533069196

Fax: (03) 93487802

This article is protected by copyright. All rights reserved 
2 Received Date : 15 -Feb-2016

3 Revised Date : 27-May-2016

4 Accepted Date: 04-Jun-2016

5 Article type : Radiology Original Article

8 Audit of CT Reporting Standards in Cases of

9 Intracerebral Haemorrhage at a Comprehensive Stroke

10 Centre in Australia

12 Christen Barras, MBBS, BMedSci, MMed, PhD, DipSurgAnat, DipOMS, FRANZCR; Hamed

13 Asadi, MD, PhD, FRANZCR; Pramit M. Phal MBBS, FRANZCR; Brian M Tress, MD, FRCR,

14 FRANZCR; Stephen Davis MD, FRACP, FRCP (Edin); Patricia M Desmond MSc, MD,

15 FRANZCR

Abstract:

Introduction: Multiple CT-derived biomarkers that are predictive of intracerebral hemorrhage (ICH) growth and outcome have been described in the literature, but the extent to which these appear in imaging reports of ICH is unknown. The aim of this retrospective process audit was to determine which of the known predictors of $\mathrm{ICH}$ outcome were recorded in reports of the disease, with a view to providing reporting recommendations, as appropriate.

Method: We examined the initial CT report of patients diagnosed with $\mathrm{ICH}$ presenting to a metropolitan comprehensive stroke centre and meeting inclusion criteria during the audit period between March $1^{\text {st }}, 2013$ to February $28^{\text {th }}$ 2014. Each report was assessed for the inclusion of the following $\mathrm{ICH}$ characteristics: number of measurement dimensions; volume; location; hydrocephalus; shape; density; 'CTA spot sign' (where CTA was performed). 
30 Results: A total of 100 patients met audit inclusion criteria. At least one ICH dimension was

31 recorded in $90 \%$ of reports, however, $39 \%$ did not include measurements in three dimensions

32 and volume was reported in just $6 \%$. No ICH dimension was recorded in $10 \%$ of reports. With

33 the exception of density and shape, reporting of other CT features exceeded $95 \%$. Where CTA

34 was performed (58\%), 14/58 (24\%) reported the 'CTA spot sign' status.

Conclusion: In this audit, volume was the most under-reported of the established ICH characteristics predictive of ICH outcome. Readily calculated from multiplanar reformats using the $\mathrm{ABC} / 2$ technique, the routine reporting of $\mathrm{ICH}$ volume is recommended. More reporting attention to $\mathrm{ICH}$ density heterogeneity and shape irregularity is encouraged, given their emerging importance. Where acute CTA is performed, the presence of any dynamic haemorrhage (CTA spot sign) should be reported.

Key Words:

Audit; Computed tomography; CT Angiography; Intracerebral hemorrhage; Report

Introduction:

56 Timely radiology reports targeting clinically relevant information are crucial for good patient care, for consideration of trial eligibility, medical treatment planning, assessment for potential neurosurgical intervention as well as for the purposes of resource allocation, prognostication and occasionally end-of-life decision making. Prognostically significant clinical and imaging

60 findings of intracranial haemorrhage (ICH) have been comprehensively described in the 61 literature (Table 1). 
63 Whilst previous hemostatic treatment trials in ICH have established the ability to reduce

64 hematoma growth when administered within four hours of symptom onset, ${ }^{1}$ the largest Phase

65 III trial did not achieve statistically significant clinical benefit for several reasons, including

66 inclusion of patients without evidence of active bleeding. ${ }^{2,3}$ As a result, three trials of

67 hemostatic agents based upon imaging-based treatment randomisation according to CTA spot sign status are in progress, targeting patients with imaging evidence of dynamic hemorrhage, ${ }^{4}$

69 two in North America (STOP-IT: NCT00810888; SPOTLIGHT: NCT01359202) and one in

70 Australia, (STOP-AUST: NCT01702636).

A thorough literature search found that the extent to which relevant imaging findings are reported in cases of $\mathrm{ICH}$ is unknown. The aim of this targeted retrospective process audit was to assess the reports of patients suffering $\mathrm{ICH}$ over one year of admissions at a metropolitan comprehensive stroke centre in Australia, evaluating which of the known predictors of ICH growth and outcome were included in the first imaging report provided, with a view to providing reporting recommendations for our institution and beyond, where necessary.

[INSERT TABLE 1]

Table 1. Predictors of ICH Outcome

(Modified and updated from Butcher et al. $)^{5} \mathrm{PCE}=$ post-contrast $\mathrm{CT}$ extravasation.

\section{Methods}

Patients

At our institution all patients with suspected stroke or transient ischemic attack (TIA) are referred for non-contrast CT brain. Patients with acute stroke are referred to a 'Code Stroke' service that operates 24 hours a day, all year, consisting of an experienced stroke fellow and a stroke research nurse, with continuous on-call neurologist support. Continuous radiologist or radiology registrar reporting is present in the Emergency Department. All 'Code Stroke' patients are pre-notified by the transferring ambulance and undergo expedited transfer to the Emergency CT scanner. ${ }^{28}$ All patients are screened for trial eligibility by the code stroke team on the basis of their presenting history and examination findings and all admitted stroke unit patients are entered into the stroke database. This database was utilized to identify all cases of

95 CT-demonstrated ICH over a 12 month period from March $1^{\text {st }}, 2013$ to February $28^{\text {th }} 2014$. For 
96 the ICH investigation presented, patients were included on the basis of identification of non-

97 traumatic, primary intracerebral hemorrhage identified on baseline diagnostic CT brain, within

9824 hours of symptom onset as recorded in the stroke database. In line with recommendations

99 of both European ${ }^{29}$ and American Stroke authorities, ${ }^{30}$ patients presenting to our hospital with

100 acute $\mathrm{ICH}$ within 6 hours (the period most likely to demonstrate ICH growth), undergo CT

101 angiography of the Circle of Willis as standard care, unless contraindicated or otherwise

102 avoided at the discretion of the responsible physician. No traceable patient information was

103 recorded for the purposes of this project, all results tabulated and anonymised, including

104 imaging, in keeping with standard audit procedure. No templates or mandated guidelines for

105 reporting of $\mathrm{ICH}$ were in place over the audit period. Formal institutional ethics approval for

106 this project was obtained.

107

108

109 Audit Criteria

110 All patients presenting to a metropolitan emergency department and comprehensive stroke

111 centre in Melbourne, Australia with intracerebral hemorrhage over the study period meeting

112 eligibility criteria were included in the audit. Each patient's presenting CT brain scan, at which

113 the diagnosis of $\mathrm{ICH}$ was made, and the associated radiology report relating to each patient's

$114 \mathrm{ICH}$, was scrutinised by single rater (CB). Specifically, all stated findings were confirmed or

115 queried by a single radiologist (CB) and where discrepancies arose, a final consensus was

116 achieved with a second radiologist (HA), both experienced in neuroimaging. The designation of

117 the reporting radiologist was recorded (neuroradiologist; general or other subspecialist

118 radiologist; fellow/registrar; external report). After-hours emergency department imaging

119 (Sunday-Friday 6pm-12am; Saturday 6pm-2am) was reported by an external teleradiology

120 reporting service. When co-reported, the most senior designated radiologist was recorded.

121 Patients were excluded from analysis if:

122 I. The initial CT scan that was diagnostic of ICH was not performed at the index hospital

123 (ie. cases of transfer from other hospital, with imaging performed and reported

124 elsewhere).

125 II. The CT scan revealed no evidence of $\mathrm{ICH}$ (ie. in contradistinction to the stroke

126 database) such as primary intraventricular hemorrhage or subarachnoid hemorrhage.

127 III. The patient was not recorded in the stroke database

This article is protected by copyright. All rights reserved 
128 The data recorded in this audit were as follows:

129 I. Number of dimensions of ICH measurement (none, one, two or three). Note that the

130 omission of the craniocaudal dimension may exclude the greatest ICH dimension from

131 assessment (fig 1)

132 II. Whether $\mathrm{ICH}$ volume was reported $(\mathrm{Y} / \mathrm{N})$

133 III. Whether ICH location was reported $(\mathrm{Y} / \mathrm{N})$

134 IV. Whether hydrocephalus was reported as present or absent $(\mathrm{Y} / \mathrm{N})$

$135 \quad \mathrm{~V}$. Whether intraventricular hemorrhage was reported $(\mathrm{Y} / \mathrm{N})$

136 VI. Whether ICH density was reported $(\mathrm{Y} / \mathrm{N})$

137 VII. Whether ICH shape was reported $(\mathrm{Y} / \mathrm{N})$

138 VIII. If CT angiography of the Circle of Willis was performed, whether the presence/absence of

139 the CTA 'spot sign' was reported $(\mathrm{Y} / \mathrm{N})$

[INSERT FIGURE 1]

\section{CAPTION:}

149

Where no ICH dimension was recorded, a case-by-case analysis of the precise wording of the report was invoked, and an estimate of the ICH volume was performed by a single rater ( $C B$ ) using the $A B C / 2$ formula. ${ }^{31}$ This procedure was performed to examine for any

\section{$150 \quad 3.7 \mathrm{~cm}(\mathrm{ap}) \times 4.5 \mathrm{~cm}(\mathrm{cc})$.}

\section{Results}

153 In the 12 month period, 109 patients were recorded in the hospital stroke database as having

154 been admitted with the CT-proven diagnosis of $\mathrm{ICH}$. Nine patients were excluded, leaving 100

155 patients whose imaging and accompanying radiology report were analysed. A summary

156 flowchart of the audit selection process is presented in Figure 2.

157

158 [INSERT FIGURE 2]

159 CAPTION:

This article is protected by copyright. All rights reserved 
160

161

162

163

164

165

166

167

168

169

170

171

172

173

174

175

176

177

178

179

180

181

182

183

184

185

186

187

188

189

190

191

Fig. 2 Enrolment flowchart

The reasons for exclusion were:

I. Presence of primary intraventricular hemorrhage (5 patients). Forms of intracranial hemorrhage other than ICH were not evaluated.

II. Initial CT scan, diagnostic of ICH, performed external to the index hospital i.e. patient transfer from another hospital (3 patients)

III. Ruptured aneurysm with predominantly subarachnoid hemorrhage, arguable small intracerebral hemorrhagic component (1 patient)

Reports were provided by a neuroradiologist in $44 / 100$ (44\%) of cases, a general or other subspecialty radiologist in 32/100 (32\%) cases, an external teleradiologist in 7/100 (7\%) and a registrar or fellow in 17/100 (17\%) of cases.

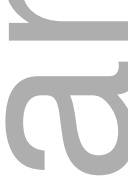

\section{Hemorrhage dimensions:}

Overall 10 patients (10\%) had no ICH dimension reported; zero had one dimension reported (0\%); 29 (29\%) had two dimensions reported; and 61 (61\%) had three dimensions reported.

Only 6 patients (6\%) had their ICH volume reported (method of calculation not known), and all cases where this occurred were in the context of reporting ICH size in three dimensions.

Of the 10 patients where no ICH dimension was recorded, the report was more likely to have been issued by a registrar or fellow $(3 / 17,17.6 \%)$ than a neuroradiologist $(3 / 44,6.8 \%)$, a general or other subspecialty radiologist $(3 / 32,9.4 \%)$ or an external teleradiologist $(1 / 7$, 14.3\%). Details of these 10 cases are presented in Table 2.

\section{Table 2: Unreported ICH dimension case-by-case analysis}

\section{Location:}

$98 / 100(98 \%)$ of patient reports made mention of the location of the haemorrhage. Of the 2 cases where ICH location was not mentioned, both were externally reported by an afterhours

This article is protected by copyright. All rights reserved 
192 reporting service. One mentioned a 'cerebral haemorrhage' (actually left temporo-parietal)

193 and one report missed a left pontine haemorrhage, subsequently re-reported as an 194 amendment by a local radiologist (within 6 hours).

195

Intraventricular hemorrhage (IVH):

$19791 / 100$ (91\%) of patient reports made mention of the presence or absence of intraventricular

198 hemorrhage. Of the 9 cases where IVH was not mentioned, none was deemed to be present.

Hydrocephalus:

$20198 / 100(98 \%)$ of patient reports made mention of the presence or absence of hydrocephalus.

202 Of the 2 cases where hydrocephalus was not mentioned, none was deemed to be present.

Shape and Density:

206 Only $1 / 100(1 \%)$ of patient reports made mention of ICH shape. Only 4/100 (4\%) of patient

207 reports made mention of $\mathrm{ICH}$ density. Three of the four cases were in the setting of anti-

208 coagulant related ICH. The fourth mentioned 'hyperacute, hypodense intraventricular blood.'

210 CTA Circle of Willis information:

$21158 / 100(58 \%)$ of patients received CTA following their ICH. Of these cases, 14/58 (24\%) of

212 reports made mention of the presence/absence of the spot sign. Where present, consensus

213 review of the accuracy of this interpretation was concordant. In one case of spot sign

214 recognition reported by a registrar and subspecialty radiologist that was not a

215 neuroradiologist, the report described presence of a 'dot sign', which is a separate

216 neuroimaging phenomenon, consisting of punctate hyperdensity within the Sylvian fissure

217 indicative of acute middle cerebral artery thrombosis ( $M 2$ segment).

218 The remainder of the $44 / 58$ (76\%) cases, the presence or absence of the CTA 'spot sign' was

219 not mentioned. The CTA spot sign was not identified by the authors in any of these cases.

220 Imaging criteria stratified by reporter designation are presented in Table 3.

\section{CAPTION:}


223 Table 3: Reported imaging features of $\mathrm{ICH}$, stratified by reporter designation. Data are

224 presented as the number (and percentage) of cases.

225

226

\section{Discussion}

227 This audit has demonstrated that whilst the majority of reports $(90 \%)$ include at least one

228 dimension of hemorrhage size, ICH volume is substantially under-reported, despite the

229 availability of multiplanar reformats and simple volume measurement techniques. Of the

230 reports analysed, $39 \%$ did not mention all three measurements and a minority (6\%)

231 commented on the estimated volume.

232 The omission of hematoma volume in reports of $\mathrm{ICH}$ is important given the predictive capacity

233 of ICH volume for morbidity and mortality in this disease, and the fundamental importance of

234 this parameter for trial eligibility. The capacity for the radiologist to easily provide accurate

235 volume data is elevated by the ready availability of multiplanar reformats that can accurately

236 depict the craniocaudal ICH volume, where previously this had to be estimated by

237 multiplication of slice thickness by the number of axial CT slices containing hematoma. In this

238 study, $29 \%$ of reports included two ICH axial dimensions. The omission of the craniocaudal

239 dimension may exclude the greatest ICH dimension from the hematoma assessment (Fig. 1).

240 In this study, the reporting radiologist was observed to under-report the importance of ICH

241 volume when the $\mathrm{ICH}$ volume was small. Of the 10 cases where no ICH dimension was

242 reported, half of these measured less than $10 \mathrm{~mL}$. ICH volume is readily calculated using the

$243 \mathrm{ABC} / 2$ formula. ${ }^{31}$ The accuracy of this formula is diminished in irregularly-shaped hemorrhages

244 that depart from the ellipsoid assumptions of this methodology, and in oral-anticoagulant-

245 related $\mathrm{ICH} .{ }^{32}$ A report omitting an $\mathrm{ICH}$ dimension was more than twice as likely to have been

246 issued by a trainee radiologist $(3 / 17,17.6 \%)$, rather than a consultant radiologist $(7 / 83,8.4 \%)$.

247 Descriptors of ICH size appear to be inconsistent and unreliably subjective. Among those

248 reports where no dimension was reported, the word 'large' was applied to ICH volumes that

249 ranged from $13.5 \mathrm{~mL}$ to $115 \mathrm{~mL}$. The largest volume for which no reference to $\mathrm{ICH}$ size was

250 made was $17.5 \mathrm{~mL}$, greater than the smallest of the subjectively labelled 'large' hemorrhages.

This article is protected by copyright. All rights reserved 
251 The frequency of reports providing specific reference to important ICH prognostic features of 252 intraventricular extension (91\%), hydrocephalus (98\%), and location (98\%) was high. These 253 imaging characteristics are recognised as relevant descriptors (whether positive or negative) in 254 this dataset.

255 The density and shape of hemorrhage were not regularly employed descriptors of ICH 256 morphology in this audit. It has been demonstrated that larger hemorrhages are more 257 irregular in shape, more heterogeneous in density and grow more. ${ }^{23}$ Though identified in two 258 of the earliest papers describing cardinal morphological characteristics of $\mathrm{ICH}^{33,34}$ density and

259 shape are possibly regarded as too subjective for reliable assessment and inclusion in reports 260 of the disease. Qualitative methodologies for shape and density categorisation ${ }^{23}$ and 261 predominantly operator-independent methodologies of $\mathrm{ICH}$ quantitative densitometry 262 measurement have been described, ${ }^{35}$ and these factors motivated the inclusion of these ICH 263 characteristics in this audit. Irregular ICH shape (but not density) was found to be 264 independently associated with poor outcome in a retrospective study of over 2000 patients. ${ }^{26}$ 265 Validation studies of qualitative and quantitative densitometry measures as predictors of 266 outcome, presence of CTA spot sign and ICH growth have been performed in different patient 267 cohorts. ${ }^{25,27,36}$ More attention to the reporting of ICH density (homogeneous/heterogeneous) 268 and shape (regular/irregular) is recommended.

269 CT angiography is being increasingly applied in the imaging assessment of acute ICH, most 270 often in comprehensive stroke centres, particularly in patients presenting within 6 hours of 271 ictus. The CTA spot sign has been identified as an independent predictor of ICH growth and 272 outcome, ${ }^{37}$ and is representative of dynamic hemorrhage due to active contrast extravasation

273 into an expanding hematoma. Three trials of hemostatic agents based on imaging 274 identification of dynamic bleeding manifest as CTA spot sign positivity are in progress. ${ }^{4,38,39}$ 275 The incidence of background intracranial vascular abnormality has been calculated at $13.1 \%$ in 276 one study of patients with basal ganglia $\mathrm{ICH}$, providing further incentive to perform CTA where 277 deemed clinically appropriate. ${ }^{40}$ Whilst there is generally consistent (>90\%) reporting of the 278 majority of relevant $\mathrm{ICH}$ growth and outcome predictors, better acknowledgement of 279 presence/absence of the CTA spot sign could be achieved in imaging reports.

280 The absence of a specific report reference to a particular descriptive characteristic of any 281 particular ICH does not necessarily mean that this characteristic was neglected by the reporter. 
282 The possibility that the imaging characteristic was assessed but not reported is an alternative 283 explanation for its omission. For example, the presence or absence of the CTA spot sign may 284 have been considered to be irrelevant (overlooking the rare case of re-bleeding ICH) where the 285 scan was performed greater than 6-12 hours post ictus, most active bleeding occurring early. 286 Time-to-CTA was not recorded as part of this audit. Time-to-scan (from symptom onset) is a 287 parameter frequently unknown by the reporting radiologist.

288 In other cases, prognostically important imaging characteristics may have been irrelevant to 289 that case (an 'irrelevant negative'), such as the presence of IVH or hydrocephalus in the setting 290 of a small lobar hemorrhage. These complexities were not explored as part of this audit. In 291 other cases, the tendency to report only positive findings, rather than a comprehensive set of 292 'relevant negatives', was evidenced by the fact that no cases of 'missed' intraventricular 293 hemorrhage or hydrocephalus were detected upon independent review of every case. 294 Accordingly, it would be unreasonable to expect that all reports include direct reference to 295 every prognostically significant imaging finding.

296 However, it is contended that ICH dimension (ideally volume) and location should be cardinal 297 features of every report of ICH. The accurate description of ICH location is not only important 298 prognostically (worse prognosis for infratentorial ICH compared to supratentorial ICH; 299 hemorrhage at eloquent foci) but enables inferences regarding aetiology (eg. hypertensive 300 basal ganglia centred ICH versus lobar amyloid angiopathy-associated ICH).

301 A possible limitation to this study is that a small number of patients presenting to the hospital 302 with $\mathrm{ICH}$ may not have been recorded in the stroke database (that is, neurosurgical or 303 emergency admissions without stroke unit consultation).

304 MRI has an important role in the imaging of $\mathrm{ICH}$, particularly in younger patients where the 305 possibility of an underlying vascular or structural abnormality (such as a tumour) is raised, but 306 assessment of MRI data was outside the scope of this audit. The extent to which the reporting 307 of the CTA spot sign or any other ICH imaging variable influences current clinical management 308 or outcome requires further study.

309 Evidence-based, prognostically significant $\mathrm{ICH}$ characteristics that are recommended for 310 inclusion in CT reports are presented in Table 4. 
311 As a result of this audit, a set of recommendations was assembled, with a view to subsequent

312 closure of the audit loop by way of a repeat audit in 12 months.

\section{Recommendations}

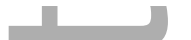

314 1. Educate radiologists and radiology registrars regarding importance of the prognostically315 significant $\mathrm{CT}$ findings in acute $\mathrm{ICH}$.

316 2. Explain the key findings relevant to $\mathrm{ICH}$ reporting to radiologists and radiology trainees by 317 reviewing the current literature in departmental meetings, including relevance of clinical 318 trials in $\mathrm{ICH}$.

3193 3. Convey the findings of this process audit to stakeholders, to remind everyone of current 320 deficiencies and encouraging methodical reporting.

321 4. Establish a template for CT reports in cases with intracerebral haemorrhage, that is user 322 friendly and easily accessible on the department's intranet.

323 5. Provide feedback to external radiologists reporting for the department and sharing the reporting guidelines and appropriate literature with them.

325 6. When all of the above has been achieved, a repeat audit in a year is recommended to assess the extent of compliance and whether reinforcement of recommendations 1-5 is required.

[INSERT TABLE 4]

330 Caption:

Table 4: Recommended CT reporting features of $\mathrm{ICH}$

\section{Conclusion}

333 Modern acute stroke management and trials of experimental therapies are founded upon

334 time-critical clinicoradiological assessment, best served by direct interaction of acute stroke 335 neurology and radiology teams. The most under-reported non-contrast CT characteristic of ICH

336 growth and outcome in this audit was ICH volume, and routine reporting of this important

337 imaging feature is recommended. More attention should be given to $\mathrm{ICH}$ density and shape in 
338

339

340 The timely provision of accurate verbal and, ultimately, written radiology reports containing

341 prognostically significant data is key to the prompt application of existing therapies,

342 prognostication, resource allocation, as well as in assessment for trial eligibility in relevant

343 centres.

344

345

346

347

348

349

350

351

352

353

354

355

356

357

358 1. Mayer SA, Brun NC, Begtrup K, Broderick J, Davis S, Diringer MN, Skolnick

reporting of the disease. Where performed acutely (especially within 6 hours), the presence of dynamic hemorrhage (the CTA 'spot sign') should be reported.

.
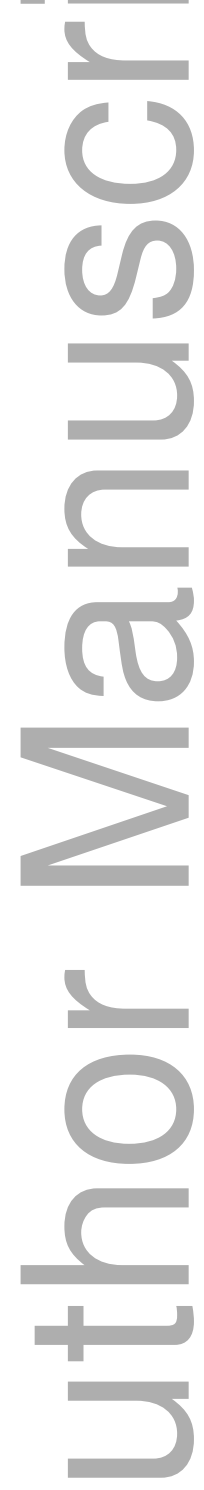

\section{References:}

BE, Steiner T. Recombinant activated factor VII for acute intracerebral hemorrhage. N Engl J Med. 2005;352:777-785. doi: 10.1056/NEJMoa042991 
361

362

363

364

365

366

367

368

369

370

371

372

373

374

375

376

377

378

379

380

381

382

383

384

385

386

387

388

389

390

2. Mayer SA, Brun NC, Begtrup K, Broderick J, Davis S, Diringer MN, Skolnick BE, Steiner T. Efficacy and safety of recombinant activated factor VII for acute intracerebral hemorrhage. N Engl J Med. 2008;358:2127-2137. doi:

10.1056/NEJMoa0707534

3. Mayer SA, Davis SM, Begtrup K, Broderick J, Diringer MN, Skolnick BE, Steiner T. Subgroup Analysis in the FAST Trial: A Subset of Intracerebral Hemorrhage Patients That Benefit from Recombinant Activated Factor VII? Stroke. 2008;39:528. doi: 10.1161/STROKEAHA.108.524470

4. Meretoja A, Churilov L, Campbell BC, et al. The Spot sign and Tranexamic acid On Preventing ICH growth - AUStralasia Trial (STOP-AUST): Protocol of a phase II randomized, placebo-controlled, double-blind, multicenter trial. Int J Stroke. 2014;9:519-524. doi: 10.1111/ijs.12132

5. Butcher K, Laidlaw J. Current intracerebral haemorrhage management. J Clin Neurosci. 2003;10:158-167. doi: 10.1016/S0967-5868(02)00324-7

6. Broderick JP, Brott TG, Duldner JE, Tomsick T, Huster G. Volume of intracerebral hemorrhage. A powerful and easy-to-use predictor of 30-day mortality. Stroke. 1993;24:987-993. doi: 10.1161/01.STR.24.7.987

7. Tuhrim S, Dambrosia JM, Price TR, Mohr JP, Wolf PA, Heyman A, Kase CS. Prediction of intracerebral hemorrhage survival. Ann Neurol. 1988;24:258-263. doi: 10.1002/ana.410240213

8. Hemphill JC, 3rd, Bonovich DC, Besmertis L, Manley GT, Johnston SC. The ICH score: a simple, reliable grading scale for intracerebral hemorrhage. Stroke. 2001;32:891-897. doi: 10.1161/01.STR.32.4.891

9. Daverat P, Castel JP, Dartigues JF, Orgogozo JM. Death and functional outcome after spontaneous intracerebral hemorrhage. A prospective study of 166 cases using multivariate analysis. Stroke. 1991;22:1-6. doi: 10.1161/01.STR.22.1.1

10. Fogelholm R, Murros K, Rissanen A, Avikainen S. Admission blood glucose and short term survival in primary intracerebral haemorrhage: a population based study. J Neurol Neurosurg Psychiatry. 2005;76:349-353. doi: 10.1136/jnnp.2003.034819 
391 11. Diringer MN, Edwards DF. Admission to a neurologic/neurosurgical intensive

392

393

394

395

396

397

398

399

400

401

402

403

404

405

406

407

408

409

410

411

412

413

414

415

416

417

418

419

420

421

422 care unit is associated with reduced mortality rate after intracerebral hemorrhage. Crit Care Med. 2001;29:635-640.

12. Zahuranec DB, Brown DL, Lisabeth LD, Gonzales NR, Longwell PJ, Smith MA, Garcia NM, Morgenstern LB. Early care limitations independently predict mortality after intracerebral hemorrhage. Neurology. 2007;68:1651-1657. doi:

10.1212/01.wnl.0000261906.93238.72

13. Davis SM, Broderick J, Hennerici M, Brun NC, Diringer MN, Mayer SA, Begtrup K, Steiner T. Hematoma growth is a determinant of mortality and poor outcome after intracerebral hemorrhage. Neurology. 2006;66:1175-1181. doi: 10.1212/01.wnl.0000208408.98482.99

14. Kim J, Smith A, Hemphill JC, 3rd, Smith WS, Lu Y, Dillon WP, Wintermark M. Contrast extravasation on CT predicts mortality in primary intracerebral hemorrhage. AJNR Am J Neuroradiol. 2008;29:520-525. doi:

10.3174/ajnr.A0859

15. Li N, Wang Y, Wang W, Ma L, Xue J, Weissenborn K, Dengler R, Worthmann H, Wang DZ, Gao P, Liu L, Zhao X. Contrast extravasation on computed tomography angiography predicts clinical outcome in primary intracerebral hemorrhage: a prospective study of 139 cases. Stroke. 2011;42:3441-3446. doi: 10.1161/STROKEAHA.111.623405

16. Hallevi H, Abraham AT, Barreto AD, Grotta JC, Savitz SI. The spot sign in intracerebral hemorrhage: the importance of looking for contrast extravasation. Cerebrovasc Dis. 2009;29:217-220. doi: 10.1159/000267842

17. Helweg-Larsen S, Sommer W, Strange P, Lester J, Boysen G. Prognosis for patients treated conservatively for spontaneous intracerebral hematomas. Stroke. 1984;15:1045-1048. doi: 10.1161/01.STR.15.6.1045

18. Gujjar AR, Deibert E, Manno EM, Duff S, Diringer MN. Mechanical ventilation for ischemic stroke and intracerebral hemorrhage: indications, timing, and outcome. Neurology. 1998;51:447-451.

19. Tuhrim S, Horowitz DR, Sacher M, Godbold JH. Volume of ventricular blood is an important determinant of outcome in supratentorial intracerebral hemorrhage. Crit Care Med. 1999;27:617-621. 
423

424

425

426

427

428

429

430

431

432

433

434

435

436

437

438

439

440

441

442

443

444

445

446

447

448

449

450

451

452

453

454

20. Haapaniemi E, Soinne L, Syrjala M, Kaste M, Tatlisumak T. Serial changes in fibrinolysis and coagulation activation markers in acute and convalescent phase of ischemic stroke. Acta Neurol Scand. 2004;110:242-247. doi: 10.1111/j.16000404.2004.00304.x

21. Rost NS, Smith EE, Chang Y, Snider RW, Chanderraj R, Schwab K, FitzMaurice E, Wendell L, Goldstein JN, Greenberg SM, Rosand J. Prediction of functional outcome in patients with primary intracerebral hemorrhage: the FUNC score. Stroke. 2008;39:2304-2309. doi:

10.1161/STROKEAHA.107.512202

22. Diringer MN, Edwards DF, Zazulia AR. Hydrocephalus: a previously unrecognized predictor of poor outcome from supratentorial intracerebral hemorrhage. Stroke. 1998;29:1352-1357.

23. Barras CD, Tress BM, Christensen S, MacGregor L, Collins M, Desmond PM, Skolnick BE, Mayer SA, Broderick JP, Diringer MN, Steiner T, Davis SM. Density and shape as CT predictors of intracerebral hemorrhage growth. Stroke. 2009;40:1325-1331. doi: 10.1161/STROKEAHA.108.536888

24. Barras CD, Tress BM, Christensen S, Collins M, Desmond PM, Skolnick BE, Mayer SA, Davis SM. Quantitative CT densitometry for predicting intracerebral hemorrhage growth. AJNR Am J Neuroradiol. 2013;34:1139-1144. doi: 10.3174/ajnr.A3375

25. Connor D, Huynh TJ, A.M. D, Dowlatshahi D, Gladstone DJ, Subramaniapillai S, Symons SP, Aviv RI. Swirls and spots: relationship between qualitative and quantitative hematoma heterogeneity, hematoma expansion, and the spot sign. Neurovascular Imaging. 2015;1:1-8. doi: 10.1186/s40809-015-0010-1

26. Delcourt C, Zhang S, Arima H, et al. Significance of Hematoma Shape and Density in Intracerebral Hemorrhage: The Intensive Blood Pressure Reduction in Acute Intracerebral Hemorrhage Trial Study. Stroke. 2016;47:1227-1232. doi: 10.1161/strokeaha.116.012921

27. Li Q, Zhang G, Xiong X, Wang XC, Yang WS, Li KW, Wei X, Xie P. Black Hole Sign: Novel Imaging Marker That Predicts Hematoma Growth in Patients With Intracerebral Hemorrhage. Stroke. 2016 doi:

10.1161/strokeaha.116.013186

This article is protected by copyright. All rights reserved 
455

456

457

458

459

460

461

462

463

464

465

466

467

468

469

470

471

472

473

474

475

476

477

478

479

480

481

482

483

484

485

486

28. Meretoja A, Weir L, Ugalde M, Yassi N, Yan B, Hand P, Truesdale M, Davis SM, Campbell BC. Helsinki model cut stroke thrombolysis delays to 25 minutes in Melbourne in only 4 months. Neurology. 2013;81:1071-1076. doi: 10.1212/WNL.0b013e3182a4a4d2

29. Stapf C, Van der Worp HB, Steiner T, Rinkel GJ, Nedeltchev K, Mast H, Dichgans M, Cordonnier C, Arnold M, Al-Shahi R. Stroke research priorities for the next decade--a supplement statement on intracranial haemorrhage.

Cerebrovasc Dis. 2007;23:318-319; author reply 319-320. doi:

\section{$10.1159 / 000098447$}

30. Priorities for clinical research in intracerebral hemorrhage: report from a National Institute of Neurological Disorders and Stroke workshop. Stroke. 2005;36:e23-41. doi: 10.1161/01.STR.0000155685.77775.4c

31. Kothari RU, Brott T, Broderick JP, Barsan WG, Sauerbeck LR, Zuccarello M, Khoury J. The ABCs of measuring intracerebral hemorrhage volumes. Stroke. 1996;27:1304-1305. doi: 10.1161/01.STR.27.8.1304

32. Huttner HB, Steiner T, Hartmann M, Kohrmann M, Juettler E, Mueller S, Wikner J, Meyding-Lamade U, Schramm P, Schwab S, Schellinger PD. Comparison of $\mathrm{ABC} / 2$ estimation technique to computer-assisted planimetric analysis in warfarin-related intracerebral parenchymal hemorrhage. Stroke. 2006;37:404-408. doi: 10.1161/01.STR.0000198806.67472.5c

33. Tans JT. Computed tomography of intracerebral hematoma. Clin Neurol Neurosurg. 1977;79:285-295.

34. Scott WR, New PF, Davis KR, Schnur JA. Computerized axial tomography of intracerebral and intraventricular hemorrhage. Radiology. 1974;112:73-80. doi: 10.1148/112.1.73

35. Barras CD, Tress BM, Christensen S, Collins M, Desmond PM, Skolnick BE, Mayer SA, Davis SM, Recombinant Activated Factor VIIIHTI. Quantitative CT densitometry for predicting intracerebral hemorrhage growth. AJNR Am J Neuroradiol. 2013;34:1139-1144. doi: 10.3174/ajnr.A3375

36. Selariu E, Zia E, Brizzi M, Abul-Kasim K. Swirl sign in intracerebral haemorrhage: definition, prevalence, reliability and prognostic value. BMC neurology. 2012;12:109. doi: 10.1186/1471-2377-12-109

This article is protected by copyright. All rights reserved 
487

488

489

490

491

492

493

494

495

496

497

498

499

500

501

502

503

504

37. Demchuk AM, Dowlatshahi D, Rodriguez-Luna D, et al. Prediction of haematoma growth and outcome in patients with intracerebral haemorrhage using the CT-angiography spot sign (PREDICT): a prospective observational study. Lancet Neurol. 2012;11:307-314. doi: 10.1016/S1474-4422(12)70038-8

38. Aviv RI, Demchuk AM. "Spot Sign" Selection of Intracerebral Hemorrhage to Guide Hemostatic Therapy.

- http://www.clinicaltrials.gov/ct2/show/NCT01359202 Published May 20, 2011. Updated January 11, 2013. Accessed 16/2/2013.

39. Jauch E, Flaherty M. The Spot Sign for Predicting and Treating ICH Growth Study "STOP-IT". http://www.clinicaltrials.gov/ct2/show/NCT00810888

Published December 15, 2008. Updated June 12, 2012. Accessed 16/2/2013.

40. Zheng T, Wang S, Barras C, Davis S, Yan B. Vascular imaging adds value in investigation of basal ganglia hemorrhage. J Clin Neurosci. 2012;19:277-280. doi: $10.1016 /$ j.jocn.2011.05.027

\section{Table 1. Predictors of ICH Outcome}

(Modified and updated from Butcher et al. $)^{5} \mathrm{PCE}=$ post-contrast $\mathrm{CT}$ extravasation.

\begin{tabular}{|c|c|c|}
\hline Indicator & $\begin{array}{l}\text { Predictors of } \\
\text { favourable outcome }\end{array}$ & $\begin{array}{l}\text { Predictors of } \\
\text { unfavourable outcome }\end{array}$ \\
\hline $\begin{array}{l}\text { Clinical } \\
\text { Glasgow coma scale } \\
\text { Intubation }{ }^{6,10} \\
\text { Age }^{8,9} \\
\text { Admission to neuro ICU }{ }^{11} \\
\text { Do-not-resuscitate order }{ }^{12} \\
\text { Imaging } \\
\text { Baseline volume } \\
\text { Hematoma growth } \\
\text { CTA 'spot sign' or PCE }{ }^{14-16} \\
\text { Intraventricular hemorrhage } \\
\text { Location of ICH }{ }^{8,20,21} \\
\text { Hydrocephalus }\end{array}$ & $\begin{array}{l}\geq 9 \\
\text { Not required } \\
\text { Younger } \\
\text { Admitted } \\
\text { Not issued early } \\
\leq 60 \mathrm{~mL} \\
\text { Absent } \\
\text { Absent } \\
\text { Absent } \\
\text { Supratentorial } \\
\text { Absent }\end{array}$ & $\begin{array}{l}\leq 8 \\
\text { Required } \\
\text { Older ( } \geq 80 \text { ) } \\
\text { Not admitted } \\
\text { Issued early } \\
\geq 61 \mathrm{~mL} \text { (91\% } \mathrm{D}_{30} \text { mortality) } \\
\text { Present } \\
\text { Present } \\
\text { Present } \\
\text { Infratentorial } \\
\text { Present }\end{array}$ \\
\hline
\end{tabular}

This article is protected by copyright. All rights reserved 
Density and shape $\mathrm{e}^{23-27}$

Homogeneous density,

regular shape
Heterogeneous density, irregular shape
505

506

507

508

509

510

511

512

513

514

515

516 Table 3. Reported imaging features of $\mathrm{ICH}$, stratified by reporter designation. Data are presented as

517 the number (and percentage) of cases.

Table 2: Case-by-case analysis of unreported ICH dimensions

\begin{tabular}{|c|c|c|}
\hline Patient number & Report reference to size & Actual size using $A B C / 2$ \\
\hline & None & $1 \mathrm{~mL}$ pontine $\mathrm{ICH}$ \\
\hline & None & $7 \mathrm{~mL}$ \\
\hline 3 & None & $8 \mathrm{~mL}$ \\
\hline 4 & None & $17.5 \mathrm{~mL}$ \\
\hline & $\begin{array}{c}\text { Predominantly IVH, very difficult to } \\
\text { measure ICH component }\end{array}$ & $1 \mathrm{~mL}$ \\
\hline & 'Very small' & $5 \mathrm{~mL}$ \\
\hline 7 & 'Large' & $13.5 \mathrm{~mL}$ \\
\hline & 'Large' & $55 \mathrm{~mL}$ \\
\hline 9 & 'Large' & $60 \mathrm{~mL}$ \\
\hline 10 & 'Large' & $115 \mathrm{~mL}$ \\
\hline
\end{tabular}




\begin{tabular}{|c|c|c|c|c|c|}
\hline r & $\begin{array}{l}\text { Neuroradiologist } \\
(\mathrm{N}=44)\end{array}$ & $\begin{array}{l}\text { General/Other } \\
\text { Subspecialty } \\
\text { Radiologist } \\
(\mathrm{N}=32)\end{array}$ & $\begin{array}{l}\text { Registrar } \\
\text { or Fellow } \\
(\mathrm{N}=17)\end{array}$ & $\begin{array}{l}\text { Teleradiologist } \\
(\mathrm{N}=7)\end{array}$ & $\begin{array}{l}\text { Total } \\
(\%)\end{array}$ \\
\hline \multicolumn{6}{|c|}{\begin{tabular}{l|l} 
ICH dimension \\
\end{tabular}} \\
\hline None & $3(7)$ & $3(9)$ & $3(18)$ & $1(14)$ & 10 \\
\hline One & $0(0)$ & $0(0)$ & $0(0)$ & $0(0)$ & 0 \\
\hline Two & $14(32)$ & $7(22)$ & $6(35)$ & $2(29)$ & 29 \\
\hline Three & $27(61)$ & $22(69)$ & $8(47)$ & $4(57)$ & 61 \\
\hline Volume & $1(2)$ & $5(16)$ & 0 & 0 & 6 \\
\hline Location & $44(100)$ & $32(100)$ & $17(100)$ & $5(71)$ & 98 \\
\hline IVH & $42(95)$ & $30(94)$ & $15(88)$ & $4(57)$ & 91 \\
\hline Hydrocephalus & $43(98)$ & $32(100)$ & $17(100)$ & $6(86)$ & 98 \\
\hline Density & $0(0)$ & $2(6)$ & $2(12)$ & $0(0)$ & 4 \\
\hline Shape & $0(0)$ & $1(3)$ & $0(0)$ & $0(0)$ & 1 \\
\hline
\end{tabular}

520

521

522

523

524

525

526

527

528

529

530

This article is protected by copyright. All rights reserved 
Table 4. Recommended CT reporting features of ICH

532

533

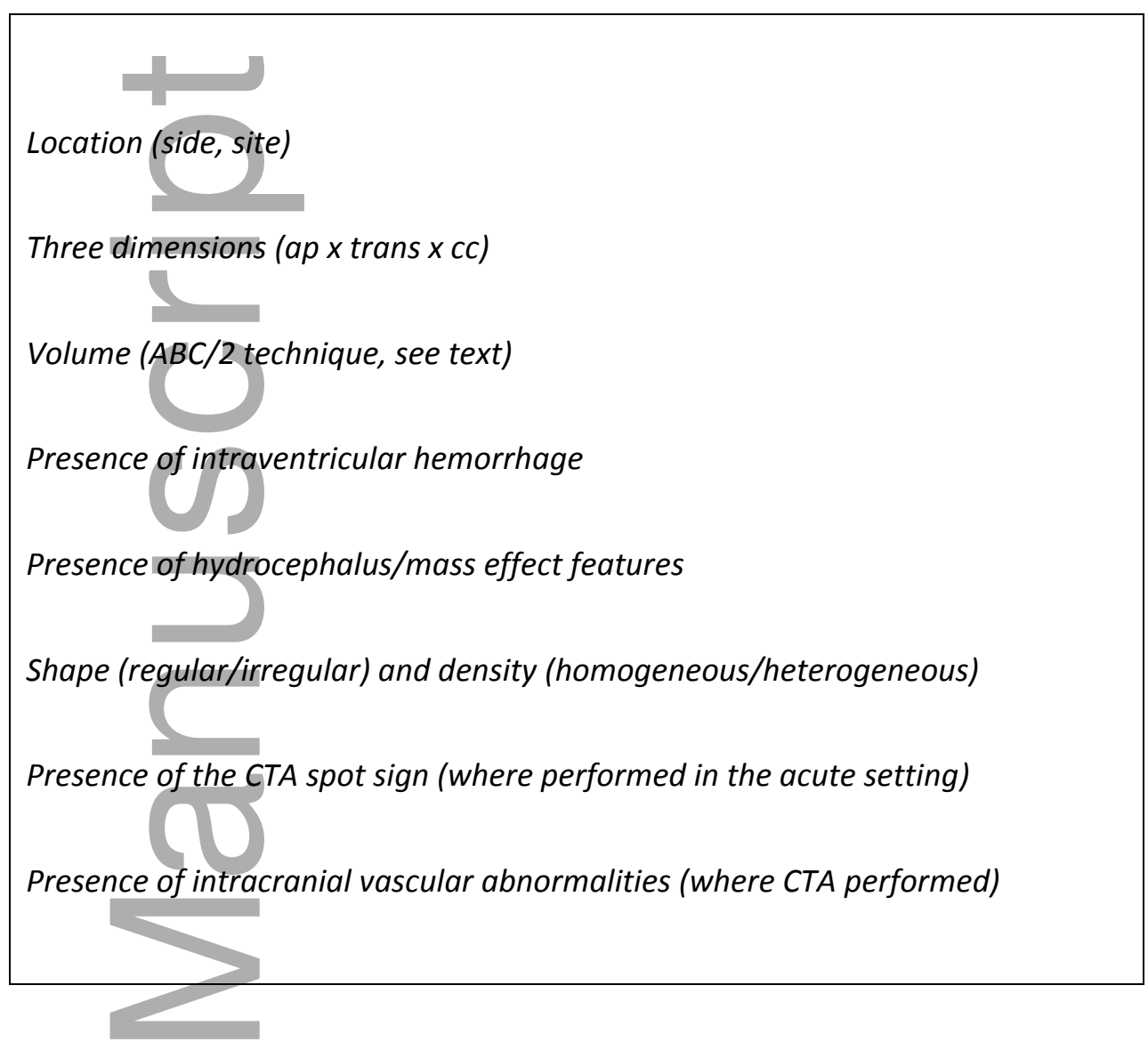

534

535

536

537
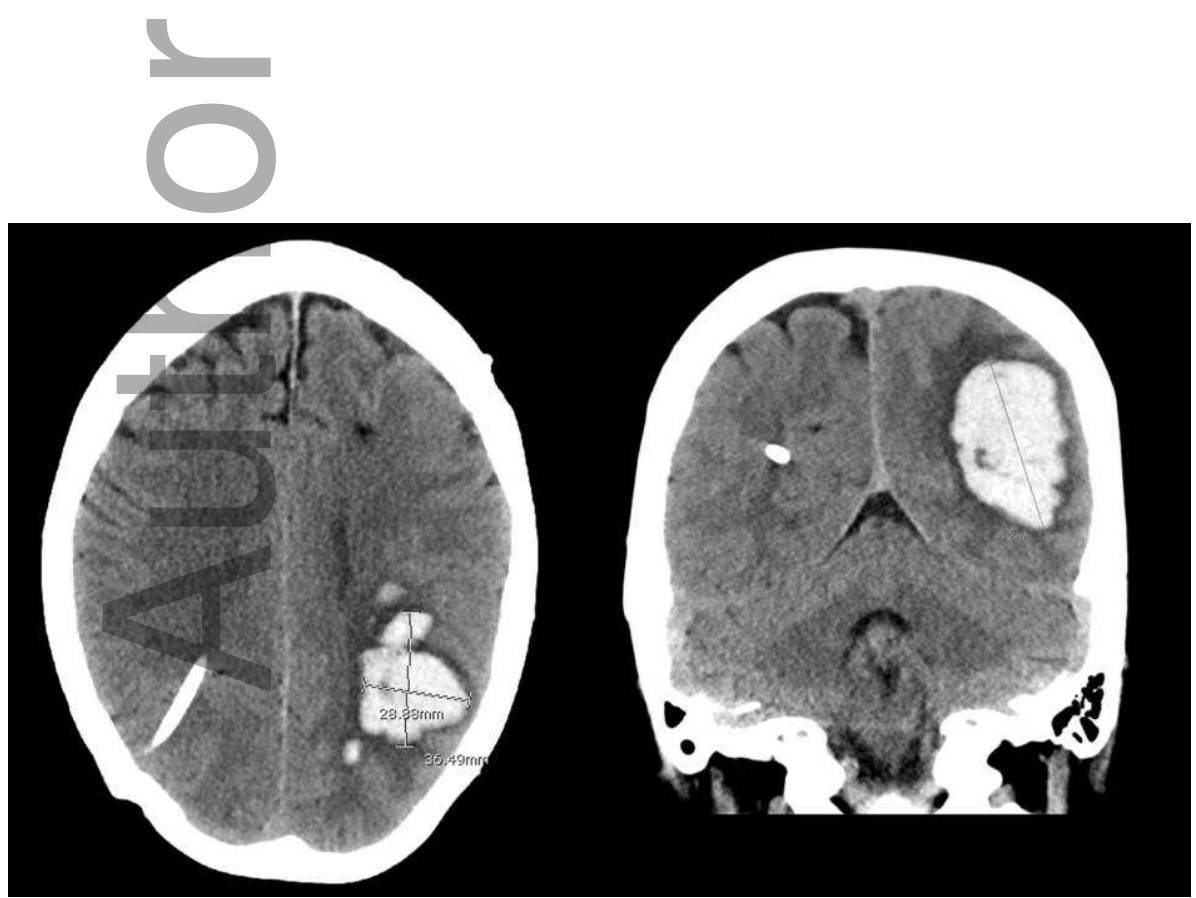

This article is protected by copyright. All rights reserved 
539 Figure 1. ICH in which the largest dimension is the coronal plane.

540 ICH dimensions $2.9 \mathrm{~cm}$ (trans) $\times 3.7 \mathrm{~cm}$ (ap) $\times 4.5 \mathrm{~cm}$ (cc).

541

542

543 Fig 2. Enrolment flowchart

\section{Total $\mathrm{ICH}^{*}$ \\ $n=109$}

*As recorded in stroke database for the audit period March $1^{\text {st }} 2013$ - February $28^{\text {th }} 2014$

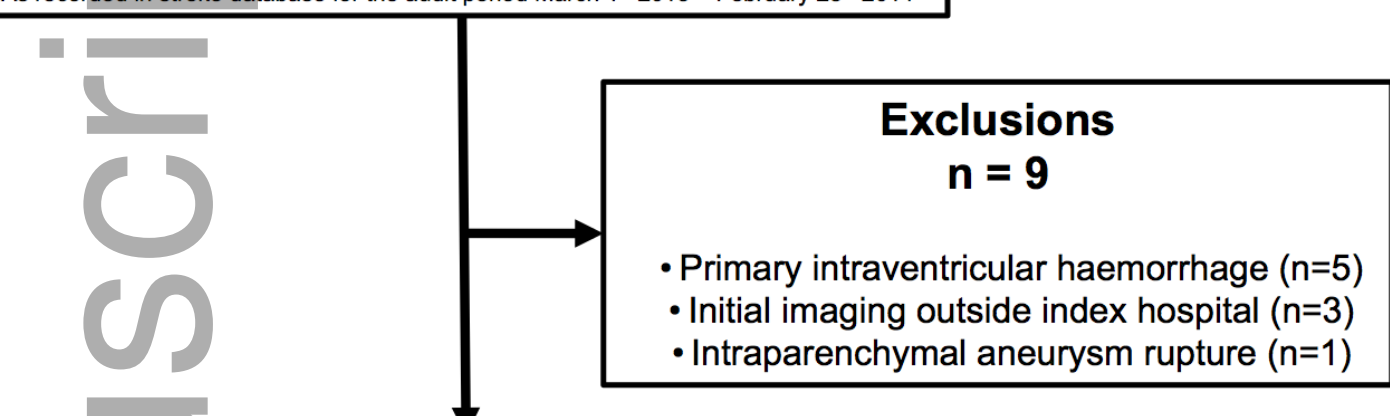

\section{Inclusions}

$\mathrm{n}=\mathbf{1 0 0}$

- CT proven $\mathrm{ICH}$, imaged at the index hospital
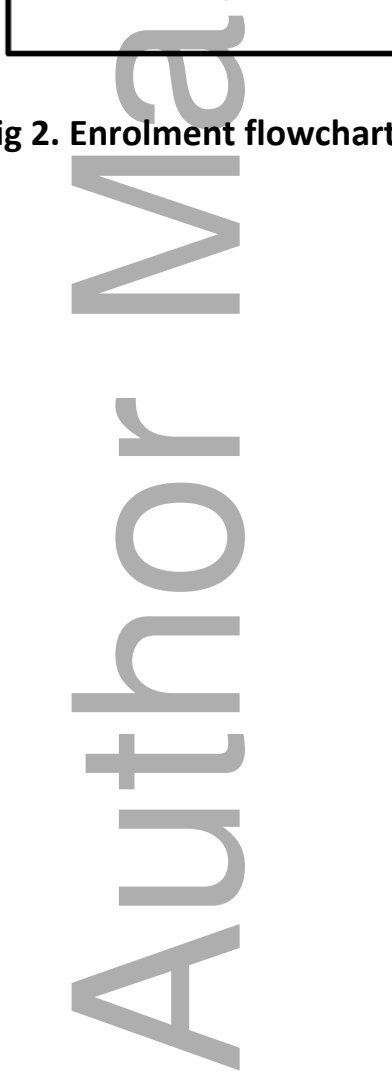

This article is protected by copyright. All rights reserved 

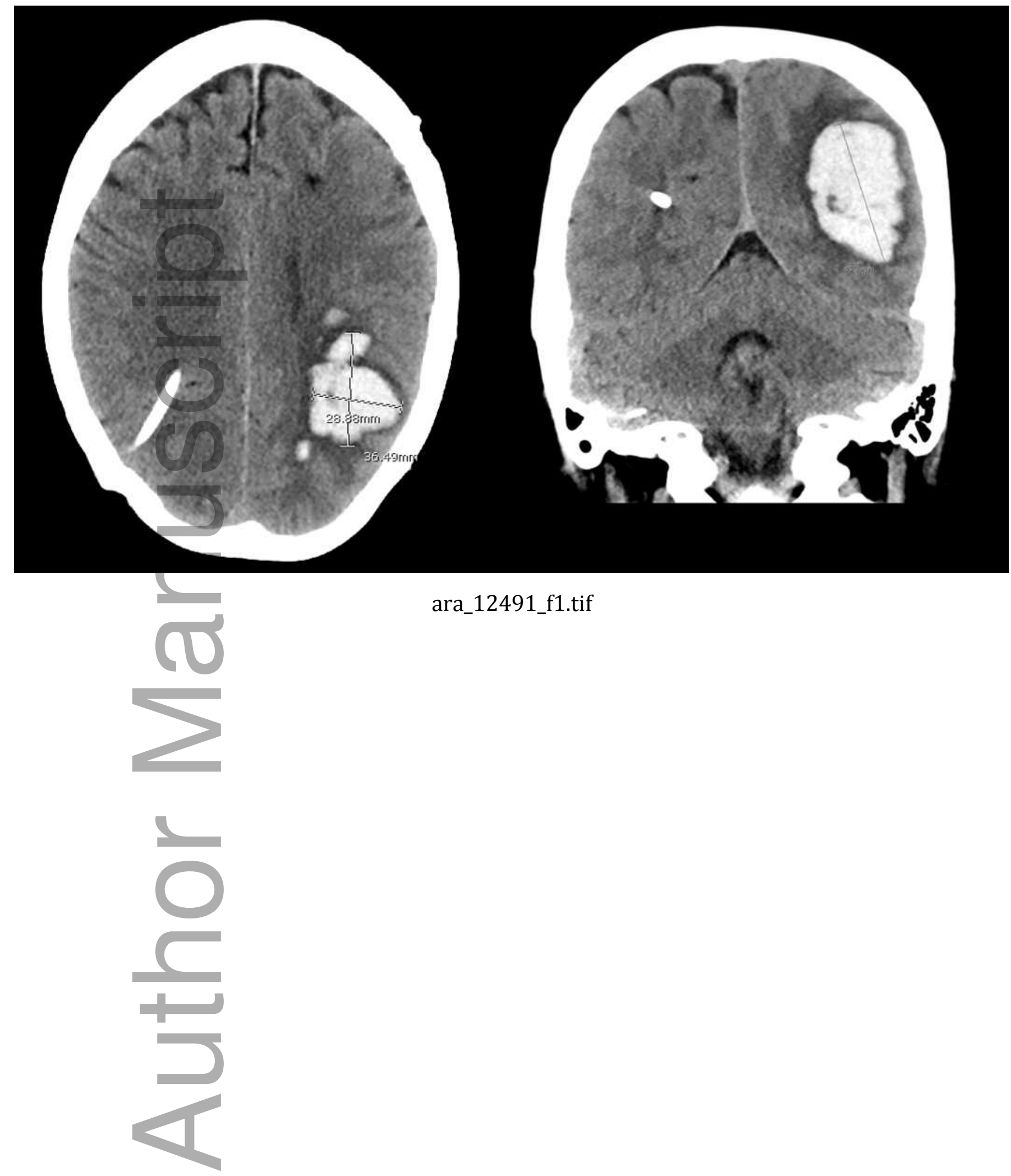

This article is protected by copyright. All rights reserved 


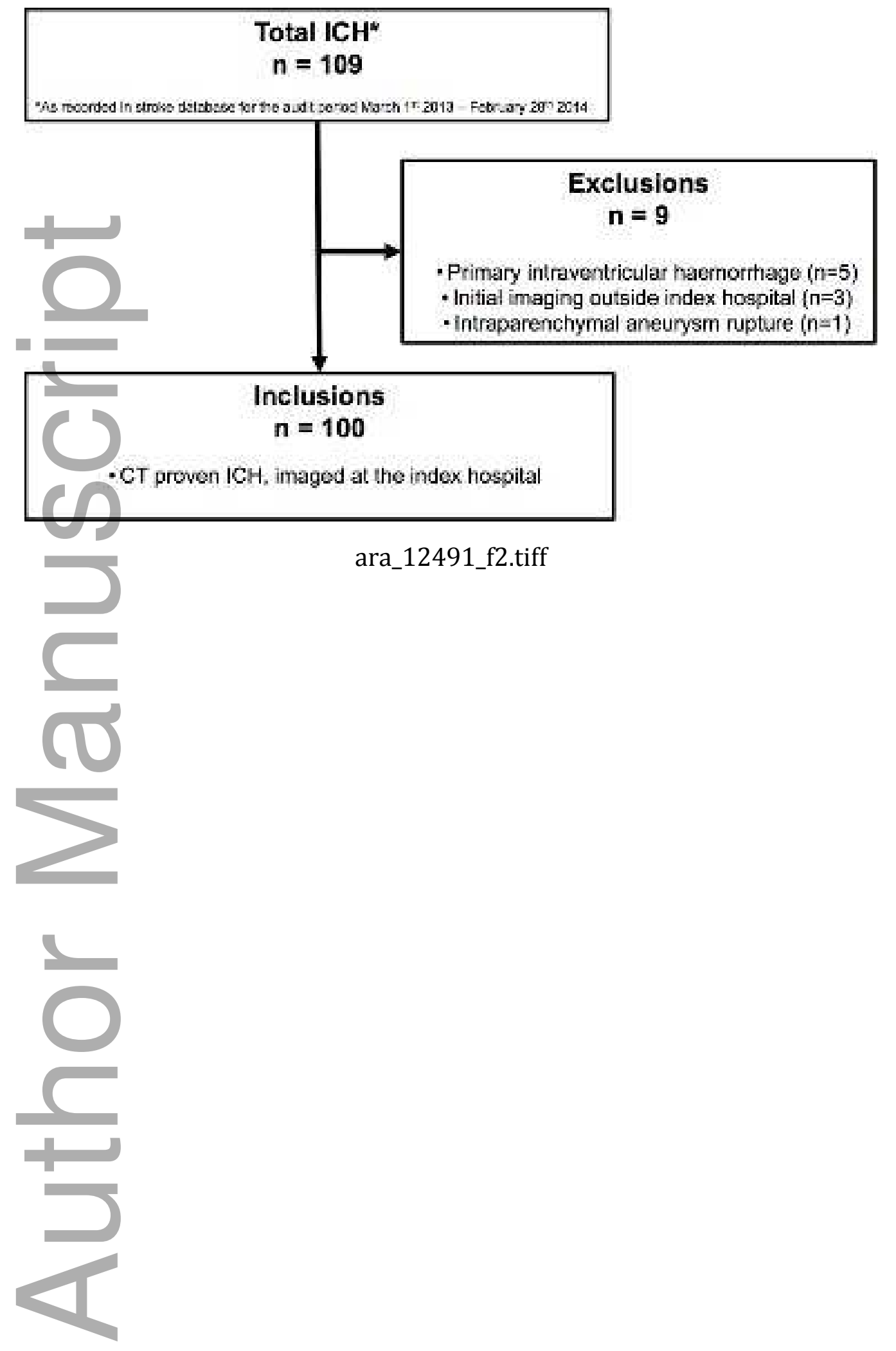

This article is protected by copyright. All rights reserved 


\section{University Library}

\section{- M M I N E R VA A gateway to Melbourne's research publications}

Minerva Access is the Institutional Repository of The University of Melbourne

Author/s:

Barras, CD;Asadi, H;Phal, PM;Tress, BM;Davis, SM;Desmond, PM

Title:

Audit of CT reporting standards in cases of intracerebral haemorrhage at a comprehensive stroke centre in Australia

Date:

2016-12-01

Citation:

Barras, C. D., Asadi, H., Phal, P. M., Tress, B. M., Davis, S. M. \& Desmond, P. M. (2016). Audit of CT reporting standards in cases of intracerebral haemorrhage at a comprehensive stroke centre in Australia. Journal of Medical Imaging and Radiation Oncology, 60 (6), pp.720-727. https://doi.org/10.1111/1754-9485.12491.

Persistent Link:

http://hdl.handle.net/11343/291931 